\title{
'N MULTIDIMENSIONELE BENADERING TOT DIE KOMMUNIKASIE VAN OU GEKANONISEERDE TEKSTE ${ }^{11}$
}

J ROUSSEAU

\begin{abstract}
A multidimensional approach towards the communication of ancient canonised texts

This article suggests that the implementation of a multidimensional approach towards ancient canonised texts is a reality-orientated, problem-solving and progressive-effective alternative to the futile exercise of a one-dimensional approach. The over-and underexposure of the text by either an absolutised text-immanent or historical analysis is comparable to someone trying to solve Rubic's cube by turning only one level of squares. The multidimensional analysis of the relief-mapping function of the static thrust, the cosmologic-orientational function of the dynamic perspective and the persuasive function of the dialectic strategy of 1 Peter, illustrated new possibilities of experiencing a meaningful communication of ancient canonised texts as "a cosmologic battle between perspectives".
\end{abstract}

\section{INLEIDING}

Enigeen met 'n bietjie ondervinding van Rubic se "frustrasie"-kubus, sal kan getuig dat dit nie moontlik is om die kubus reg te kry sonder dat al die blokkies en al die vlakke in 'n bepaalde volgorde beweeg en gerangskik word nie. Vergelykenderwys is die veelvlakkigheid en dinamiek van Rubic se kubus maar net 'n eenvoudige illustrasie van die multidimensionaliteit van alle werklikheidsverskynsels - insluitend die van tekstuele kommunikasie. ${ }^{2)}$ Daarom is dit (by nabetragting!) verstommend dat ons in die uitleg van die Bybel as ou gekanoniseerde tekste so dikwels in die slaggat getrap het om telkens een dimensie van die Bybel oor te beklemtoon ten koste van ander ewe belangrike dimensies. ${ }^{3)}$ Dit is begryplik dat dit noodwendig aanleiding sou gee tot meer of minder ernstige gebreke in die onderskeie pogings deur die eeue om die Bybel uit te lê of te laat kommunikeer.4) So het dit gebeur dat die teologiese dimensie van die Bybel onder andere tydens die Middeleeue en sedertdien, met name binne ortodokse en fundamentalistiese kringe, so oorbeklemtoon is dat die Bybel as ' $n$ bundel tydlose en uit-die-hemel-gegewe waarhede beskou is, sonder om die antiekheid en metaforiese aard van die Bybelse 
tekste te verreken. Die historiese dimensie is veral vanaf die $17 \mathrm{de}$ tot die 20ste eeu, en soos tans nog, verteenwoordig binne 'n radikaal historieskritiese benadering, dikwels so oorbeklemtoon dat die Bybel gedegradeer is tot maar net nóg 'n ou boek. Die literêr-taalkundige dimensie is veral sedert die tweede helfte van die 20 ste eeu, in aansluiting by die strukturalisme en die literatuurwetenskap, beklemtoon ten koste van die Bybei se eiesoortige perspektief asook kultuur- en tradisie-historiese milieu.

In terme van Rubic se kubus wil dit dus voorkom of ons in die verlede dikwels besig wat met die futiele poging om die kubus van tekstuele kommunikasie reg te kry deur slegs een vlak blokkies aanhoudend te draai. Myns insiens is die uitdaging eerder om te fokus op die interrelasies en funksionele prosesse binne die onderskeie dimensies van tekstuele kommunikasie. Sodoende kan ons poog om op 'n geintegreerde wyse rekenskap te gee van die kommunikasieproses in sy totaliteit. Dit beteken dat ons noodwendig sal moet aansluit by die insigte wat met die semiotiek, literatuurwetenskap en met name die kommunikasiekunde vir die kommunikasie van ou gekanoniseerde tekste bied..$^{5)}$ Uiteraard sal ons hierdie insigte weer in verband moet bring met die resultate wat die navorsingsgeskiedenis van die Bybelwetenskappe ons bied rakende die teologiese, historiese en literêr-taalkundige dimensies van Bybelste tekste.

1. Die multidimensionaliteit van tekste: insigte vanuit die semiotiek, literatuurwetenskap en kommunikasiekunde

In die kommunikasiemodelle van die laaste paar dekades is daar toenemend klem gelê op die kompleksiteit en multidimensionaliteit van die kommunikasieproses. Vir die doeleindes van hierdie artikel sal ek volstaan met 'n skematiese voorstelling van my kommunikasiemodel wat gebaseer is op die insigte van Maletzke, Plett en Grosse. ${ }^{6)}$ Die kommunikasieproses kan verdeel word in statiese, dinamiese en dialektiese komponente. Die statiese komponent $(A)$ verteenwoordig die basiese elemente wat noodsaaklik is vir kommunikasie. Die dinamiese komponent $(B)$ het weer te doen met die unieke bydrae van elke element tot die kommunikasieproses, terwyl die dialektiese komponent (C) die verhouding (dialektiek) van die unieke (dinamiese) elemente (statiese) tot mekaar beskryf. Dit korreleer weer eens op 'n merkwaardige wyse met Rubic se kubus wat slegs reggekry kan word indien al die blokkies (statiese elemente) hul unieke (dinamiese) posisies in verhouding (dialekties) tot die ander sou inneem deur hulle kronologies te orden. Uit 
die skematiese voorstelling blyk dit dan inderdaad dat daar slegs van kommunikasie sprake kan wees indien al drie komponente in 'n bepaalde volgorde verreken word. Ons kom aanstons terug op wat die "volgorde" van hierdie komponente met betrekking tot die kommunikasie van ou tekste sou beteken.

\section{A. STATIESE KOMPONENT}
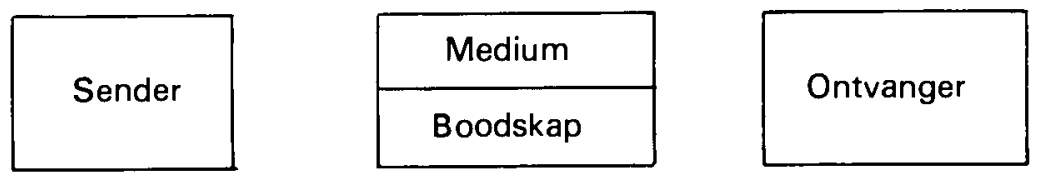

\section{B. DINAMIESE KOMPONENT}

Sender

1. Perspektief

2. Psigologiese bepaaldheid

3. Sosiologiese bepaaldheid
Medium

1. Kode

2. Medium

3. Konvensies

*Mikro

* Makro
Ontvanger

1. Perspektief

2. Psigologiese bepaaldheid

3. Sosiologiese bepaaldheid

\section{DIALEKTIESE KOMPONENT}

Sender-Medium

1. Sender se kodering * (Seleksie van) boodskap * (Ordening van) en medium

*Perspektiwiese (sosio- en psigologiese) konvensies

2. Beperkinge van boodskap en medium op sender

*Taalkonvensies

* Literêre konvensies

3. Steurnisse mbt 1 en 2

* Swak kodering

* Ignoreer konvensies
Ontvanger-Medium

1. Ontvanger se dekodering * (Seleksie van) boodskap * (Ervaring van) en medium * Perspektiwiese (sosio- en psigologiese) konvensies

2. Beperkinge van boodskap en medium op ontvanger

*Taalkonvensies

* Literêre konvensies

3. Steurnisse mbt 1 en 2

*Swak dekodering

*Onkunde oor konvensies 
1. Dialektiek binne teks: geimpliseerd

* Geïmpliseerde sender se verhouding met geïmpliseerde ontvanger en omgekeerd

2. Dialektiek buite teks: werklik

*Werklike sender se verhouding met werklike ontvangers en omgekeerd *Werklike ontvanger se verhouding met geïmpliseerde sender en ontvanger en omgekeerd

3. Steurnisse mbt 1 en 2

* Kommunikasiesteurnisse tussen sender en ontvangers

4. Terugvoer itv $1-3$

*Voortgesette kommunikasie tussen sender en ontvangers

Vergelyk mens hierdie kommunikasiemodel met die insigte van die semiotiek en literatuurwetenskap blyk die toepaslikheid en moontlikhede van die model baie duidelik. Om hierdie ooreenstemminge uit te wys, sluit ek aan by Heinrich Plett wat reeds in sy geïntegreerde kommunikasiemodel die merkwaardige ooreenstemminge tussen die tradisionele literêre modelle en semiotiese onderskeidinge uitgewys het." "Sintaksis" as 'n semiotiese onderskeiding wat die relasie tussen tekens beskryf, het belangrike raakpunte met die "objektiewe" literêre model (d i die "ou" siening van retoriek as staties). "Semantiek" as 'n semiotiese onderskeiding wat die relasie tussen tekens en hulle verwysing beskryf, stem weer merkwaardig ooreen met die "mimetiese" literêre model ( $\mathrm{d}$ i die siening van literatuur as ' $\mathrm{n}$ dinamiese spieëlbeeld van die werklikheid). So is ook die "pragmatiek" as die semiotiese onderskeiding wat die relasie tussen tekens en hulle interpreteerders beskryf, vergelykbaar met die "ekspressiewe" en "reseptiewe" literêre modelle (d $\mathrm{i}$ die siening van literatuur in sy dialektiese verhouding met die skrywers en lesers onderskeidelik). Alhoewel hierdie ooreenstemminge nie volledig saamval en nie in alle opsigte slaag nie, bevestig die navorsingsgeskiedenis van die semiotiek, literatuurwetenskap en die kommunikasiekunde minstens dat die statiese, dinamiese en dialektiese komponente noodsaaklik blyk te wees vir die kommunikasieproses in die algemeen.

Die raakpunte met die navorsingsgeskiedenis van die Bibliologiese vakke is eweneens merkwaardig. In die uitwys van hierdie ooreen- 
stemminge is dit egter belangrik dat ons daarmee rekening sal hou dat in die kommunikasie van geskrewe tekste (soos die van die Bybel) die oorspronklike senders (die skrywers) hulle identiteit laat opgaan het in hulle geskrifte wat sodoende die "sekondêre" senders word. Met ou geskrewe tekste (soos die van die Bybel) verkeer mens in elk geval in die situasie dat die oorspronklike skrywers lank reeds nie meer leef nie. Dit het die implikasie dat die statiese elemente in die kommunikasieproses beperk is tot die onderskeie Bybelse tekste (wat tegelyk die sender, medium en boodskap verteenwoordig) en hulle ontvangers (waarvan die primêre ontvangers ook lank reeds nie meer met ons is nie). Hierdie toedrag van sake noodsaak dat die staties gestolde (die geskrewe) tekste 'n definitiewe prioriteit in die kronologiese ordening en analise van die kommunikasiegebeure sal hê. Dit is dan inderdaad die prioriteit wat die literêr-taalkundige analise moet inneem in ons uitleg van Bybelse tekste. Die historiese dimensie dra op sy beurt weer veral daartoe by om die dinamiese komponent van Bybelse tekste te ontbloot - met name die uniekheid van en die dinamiek agter die tradisie- en kultuur-historiese wêreld daarvan. Sonder die analise van die dialektiese dimensie is die kommunikasieproses egter onvoltooid. Dit vereis, laastens, om te fokus op die teologiese dimensie in terme van die kommunikasiestrategieë onderliggend aan die boodskap van die onderskeie geskrifte enersyds, en die dialektiek met die geïmpliseerde en werklike ontvangers daarvan, andersyds.

Alhoewel ons in den brede die statiese, dinamiese en dialektiese komponente en hulle onderskeie funksies in die kommunikasieproses kon koppel aan die taalkundige, historiese en teologiese dimensies van Bybelse tekste onderskeidelik, sal die ervare eksegeet dadelik wou byvoeg dat daar tog statiese, dinamiese en dialektiese manifestasies (die modi) in al drie dimensies voorkom. Dit blyk dus of die kubus van tekstuele kommunikasie soos volg voorgestel kon word in die lig van die raakvlakke wat ons tussen die Bybelwetenskappe, semiotiek, literatuurwetenskap en kommunikasiekunde uitgewys het: ${ }^{8}$ )

DIMENSIES

\begin{tabular}{|c|c|c|c|}
\hline (KOMPONENTE) & TEKSTUELE & HISTORIESE & TEOGOGIESE \\
\hline SINTAKTIES & $\begin{array}{c}\text { "Dwang" } \\
\text { (STATIES) } \\
\text { reliëfkarterend }\end{array}$ & $\vdots$ & "Perspektief" \\
\hline
\end{tabular}


Ten einde hierdie ingewikkelde netwerk van tekstuele kommunikasie te vereenvoudig, het ek die begrippe "statiese dwang" (geregtigheid), "dinamiese perspektief" en "dialektiese strategie" voorgestel as verteenwoordigend van die statiese, dinamiese en dialektiese komponente van die onderskeie dimensies en modi. In my analise van die eerste Petrusbrief het dit geblyk dat die analise van elkeen van die drie komponente in die laaste instansie ' $n$ definitiewe en noodsaaklike proses in die kommunikasiegebeure verteenwoordig. Die analise van die statiese komponente het die funksie om die reliëf va die teksdwang te belig. Die analise van die dinamiese komponent ontbloot die perspektiwiese oriëntasie van die teks. Die analise van die dialektiese komponent verraai die strategie van die teks, naamlik om konflik tussen die perspektiewe van die teks en die van die lesers te ontlok.

Alhoewel mens nog ander begrippe sou kon onderskei (Rubic se kubus het immers ses vlakke!?), is die verrekening van hierdie drie begrippe, wat onderskeidelik die drie basiese komponente en prosesse in die kommunikasiegebeure verteenwoordig, na my mening die minimumvereistes vir die sinvolle kommunikasie van ou tekste. Dit word nie alleen bevestig deur die navorsingsgeskiedenis van die semiotiek, linguistiek, literatuur- en Bybelwetenskappe nie, maar ook deur retoriese, verbale, nie-verbale, mondelinge en skriftelike kommunikasieteorieë.

\section{2. 'n Multidimensionele oefenlopie in die kommunikasie van ou gekanoniseerde tekste: die "dwang, perspektief en strategie" van die eerste Petrusbrief}

Kom ons kyk illustratief hoe hierdie begrippe en die onderskeie kommunikasieprosesse wat hulle verteenwoordig, die multidimensionaliteit van 1 Petrus belig en sinvolle kommunikasie tussen hierdie ou gekanoniseerde geskrif en moderne (sekondêre) lesers moontlik sou kon maak. ${ }^{91}$

\subsection{Die reliëfkarterende funksie van die statiese dwang}

Die begrip "statiese dwang" wil die eenvoudige beginsel illustreer dat 'n teks nie ' $n$ "pannekoek" is nie. ${ }^{10)}$ Daarom moet Bybellesers nie dink omdat 'n geskrif op 'n plat vlak (papier) geskryf is, dat elke woord en vers ewe belangrik is nie. Hierdie beginsel kan selfs vir ' $n$ kind verduidelik word deur die groot druk, vet druk en fyn druk van 'n koerant as illustrasie te gebruik. Die groot druk en fyn druk dien gewoonlik as sleutel en opsomming van die bepaalde berig in die koerant. 
Wanneer ons op 'n meer gekontroleerde wyse die reliëf van 'n teks (die statiese komponent) wil bepaal, sou ons van verskillende metodes gebruik kon maak om die pieke, plato's en dale van ons teks te karteer. Dit blyk of ons minstens 'n kronologiese (.1), hiërargiese (.2), mosaïese (.3) en estetiese (.4) reliëf in 1 Petrus sou kon onderskei. ${ }^{11)}$ Uiteraard kan ons in hierdie artikel nie ingaan op die analise en kriteria van die sintaktiese, semantiese en pragmatiese ekstensie, koherensie en demarkasie van die statiese dwang van 1 Petrus nie ${ }^{12}$, maar sal ons noodgedwonge moet volstaan met die resultate van my analise.

2.1.1 'n Redevoeringsanalise van 1 Petrus het uitgewys dat perikope I $(1: 1-2), V(2: 11-12)$ en XVII $(5: 12-14)$ van die belangrikste bakens vir die kronologiese dwang van die teks verteenwoordig.

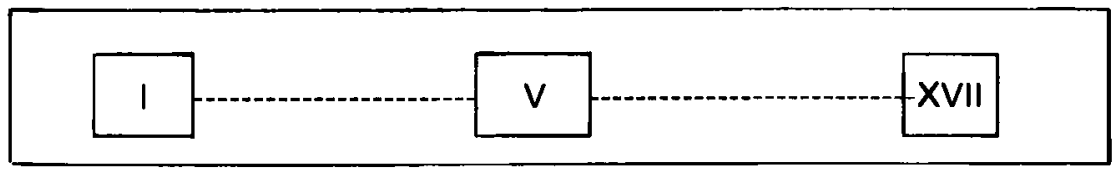

Hierdie kronologiese reliëf is nie alleen gegrond op die resultate van 'n gedetailleerde sintaktiese, semantiese en pragmatiese analise van die tekstuele dimensie nie, maar ook op die voor-die-hand-liggende insig dat die begin en einde van ' $n$ teks uiters belangrik is. Indien ' $n$ skrywer met sy lesers wil kommunikeer is dit belangrik dat hy van meet af aan belangrike rigtingwysers sal gee of 'n bepaalde verwagting sal skep wat sy boodskap sal dien. Net so moet die skrywer verseker dat die slot sy boodskap op ' $n$ treffende wyse onderstreep. Hierdie kommunikasiebeginsel is eenvoudig genoeg vir kinders'om te begryp en toe te pas.

2.1.2 In my analise van 1 Petrus het ek egter ook probeer rekenskap gee van die seleksie en weglating van motiewe en temas, asook die swaartepunte en struktuur van perikope en blokke binne 1 Petrus. Dit het geblyk dat die hiërargiese struktuur van hierdie brief ' $n$ uitgebreide chiasme en ringskomposisie vertoon: 


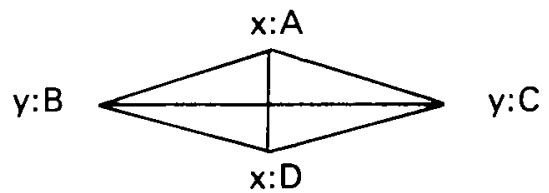

* INLEIDING: PETRUS AAN DIE UITVERKORE VREEMDELINGE $(1: 1-2)$

A: Aanvaar God se Vaderskap en julle broederskap in Christus (te midde van julle lyding) $(1: 1-2: 10)$

* aanvaar julle status as vreemdelinge \& bywoners (2:11-12)

B: Aanvaar julle unieke lewenstyl teenoor buitestaanders (selfs al moet julle soos Christus ly) (2:13-3:12)

C: Aanvaar julle lyding onder die buitestaanders (ongelowiges) ter wille van Christus (maar behou julle unieke lewenstyl as 'n broederskap van gelowiges) (3:13-4:19)

D: Aanvaar julle broederskap en God se Vaderskap (te midde van julle lyding) $(5: 1-11)$

* afsluiting: eK het Julle VermaAn maAR ook VerSEKER VAN DIE GENADE WAARIN JULLE STAAN - VREDE IN CHRISTUS!! (5:12-14)

2.1.3 Die mosaïese reliëf van 1 Petrus het te make met die mosaïek van tradisiemateriaal in die brief. Met behulp van literêre kritiek (d i bronnekritiek) is vasgestel dat daar aanhalings, frases en woorde vanuit die Ou Testament, Judaïsme, Hellenisme en Christendom in die gestolde teks van die brief ingebou is.

\section{OU-TESTAMENTIES \\ JUDAIISTIES \\ HELLENISTIES \\ CHRISTELIK}

2.1.4 Deur te fokus op die kronologiese, hiërargiese en mosaïese reliëf van die statiese teksdwang word daar gewaak om (soos dikwels in die verledel een faset of tema ten koste van ander legitieme fasette en temas te verabsoluteer. So gesien, word die legitieme meerduidigheid van tekste nie as 'n probleem ervaar nie, maar is dit 'n uitdaging om die interafhanklikheid van die mikro- en makroteks te verklaar. Uiteindelik laat dit ook reg geskied aan die estetiese geheelbeeld en reliëf van die teks. Die multidimensionele analise van die reliëf (kronologies, hiërargies en mosaïes) het aangetoon dat die sleutel tot die reliëf van 1 Petrus geleë is in die oksimoron, "uitverkore vreemdelinge" l'eklektois parepidēmois - 
$v g \mid 1: 11$. 'n "Oksimoron" is 'n stilisties-estetiese en paradoksale woordpaar wat sinduidend is vir die paradoks en onverstaanbaarheid van die lewe. Dit kom veral in godsdienstige geskrifte voor. Dit blyk dus of die skrywer die interafhanklikheid van hierdie woordpaar ('eklektoîs parepidēmois) as meestersimbole (natuurlik saam met ander aanverwante metafore) gebruik het om sin en betekenis aan die paradoksale bestaan van sy veronderstelde lesers te gee. Hierdie paradoks veronderstel lesers wat bekend staan as kinders van God, maar tog daagliks ly en swaarkry. Nie alleen word hierdie paradoks veral in perikope I, V en XVII beklemtoon nie, dit blyk ook uit die chiastiese en semantiese spanning van die brief as geheel, asook in die indikatief-imperatief dialektiek wat onderliggend is aan die estetika van die hele brief. Die veronderstelde lesers sou moes aanvaar dat hulle onverklaarbare lewensomstandighede alleen te begrype is daarin dat hulle vreemdelingskap onlosmaaklik verbonde is aan hulle uitverkiesing, en omgekeerd. Hierdie teenstrydigheid word ten diepste begrond in die Christologiese perspektief wat hierdie statiese dwang van 1 Petrus ten grondslag lê.

\subsection{Die kosmologies-oriënterende funksie van die dinamiese perspektief}

Die begrip "dinamiese perspektief" wil eenvoudig uitdrukking gee aan die beginsel dat alle tekste 'n "hart" het. In terme van kommunikasie beteken dit dat elke mens sin gee aan of kommunikeer met sy wêreld vanuit sy "hart" of bepaalde lewensperspektief (d i "ultimate commitment" of lewens- en wêreldbeskouing). Hierdie insig is gegrond in die waarneming dat die mens se lewensperspektief die funksie het om as oriëntasie te dien vir sy interaksie met sy wêreld (kosmos). ${ }^{13)}$ Georiënteer aan en in diens van hierdie lewensperspektief onderskei ek verder 'n reeks "meestersimbole" - dit is geykte of tradisionele simbole wat gedragsbepalend en sinduidend vir ' $n$ bepaalde gemeenskap is. ${ }^{14)}$

In die analise van 1 Petrus het dit geblyk dat die hart of oriëntasie (die dinamiese komponent) van 'n geskrif op verskeie wyses manifesteer, naamlik via die manifestasie van die meestersimbole in die teksdwang, die omskrywing van die sosiologiese rolle en interpersoonlike verhoudings in die geskrif, die herinterpretasie van die tradisie-materiaal asook die kultuur-historiese leefwêreld. Hierdie oriëntasie word dan uiteindelik ook in die kanoniseringsproses bekragtig of verwerp.

2.2.1 Dit is onvermydelik dat die kosmologiese perspektief wat ' $n$ geskrif ten grondslag lê, in die finale analise van die statiese dwang van 'n geskrif na vore sal kom. Ons het reeds in die bespreking van die 
statiese gerigtheid van 1 Petrus vooruitgegryp deur te sê dat dit 'n Christologiese perspektief het. Dit kan maklik deur die gewone Bybelleser raakgesien word in die motivering wat vir verskillende sake in ' $n$ geskrif gegee word. So begrond die skrywer van 1 Petrus nie alleen sy gesag met die woorde Pétros apóstolos 'lésoû Christoû nie, maar die meestersimbole "uitverkore vreemdelinge" is ook Christologies georiënteer. Dit blyk baie duidelik dwarsdeur die brief maar veral in 2:1-10 waar Christus by herhaling die "uitverkore en kosbare hoeksteen" (lithon 'akrogōniaîon 'eklektón 'éntimon - vgl 2:6) - van God se kant gesien (pará dè theō 'eklektón 'éntimon - vgl 2:4) - maar terselfdertyd die "verwerpte steen" (líthos hón 'apedokímasan - vgl 2:7) en "rots van struikeling" (lithos proskómmatos - vgl 2:8) - van die ongelowige se kant gesien ('apistoûsin de - vgl 2:7 asook 2:4) genoem word. Die paradoksale status van die geadresseerdes is dus begrond (georiënteer!) in die paradoks van die persoon Jesus Christus. In Christus is die diepste sin van hulle bestaan dus te vind. So word sowel die uitverkorenheid (met aanverwante begrippe soos kaleó, cháris, 'éleos, sōtēría, 'anagennèsas, lutróō, en so meer) en vreemdelingskap (met aanverwante begrippe soos paroikía, xenizō, páschō, peirasmós, blasfēmeō, maar by implikasie ook hágios, katharōs, en so meer) Christologies georiënteer. Daarom kan die brief dan ook treffend afsluit met die kernagtige maar allesomvattende kosmologiese perspektief van die teks: "Vrede vir julle almal wat in Christus is" (elrēnē humîn pásin toîs en Christō - vgl 5:14).

2.2.2 Die Christologiese bepaaldheid van die tekstuele wêreld van 1 Petrus word veral treffend uitgebeeld in die verhoudinge van die verskillende aktante tot mekaar. Dit kan met behulp van ' $n$ aktante-analise en hul simboliese rolle bepaal word.16) Petrus, die apostel:broer en mede-ouderling:getuie in Christus, skryf aan die mede-uitverkorene: vreemdelinge:broers:geliefdes in Christus. Hy verseker hulle dat Christus die Here:Lewende Woord:Hoeksteen:Voorbeeld:Herder en Opsiener hulle vrygekoop, wederbaar, 'n voorbeeld gestel en versorg het. Dit is deur die geadresseerdes se verbintenis aan Christus dat hulle pasgebore babas en lewende stene is wat volg in die voetspore van die paradoksale kruisiging en verheerliking van Jesus Christus, hulle Here. Deur Christus het hulle dan ook die werklikheid van God as Vader:Regter:Skepper leer ken wat hulle deur Christus gekies het as sy kinders:mense:volk:familie: priesterdom om Hom lief te hê en te dien ten spyte van hulle ervaring van lyding:vervolging:laster en diskriminasie van die heidene:ongelowiges: buitestaanders. Dit is dan juis in hulle identiteit van "uitverkore vreemdelinge" (wat hulle deel met Christus) dat hulle lewensin kan ervaar. 
Soos Christus in 'n oënskynlik onregverdige en sinlose kruisdood nog steeds kon vashou aan God as die genadige Vader en regverdige Regter ( vgl 2:21-25), net so moes die geadresseerdes in hulle omstandighede die diepste sin van hulle lewe vind in hierdie Godservaring soos uitgeleef en bemiddel deur Jesus Christus.

Geen wonder dan dat die kosmologiese tydsorde waarin die aktante hulself bevind ook Christologies gedefinieer word nie. So is daar sprake van die tyd voor en na Christus se koms asook die heerlike "nou" dat hy reeds gekom het ( $v g \mid 1: 10-12$ ). Die aktante word dan beskryf in terme van die tyd wat hulle as ongelowiges ( $\mathrm{d} i$ ongeloof in Christus) geleef het (vgl 1:14, 18 en 2:9-10), "nou" dat hulle deel van God se volk geword het (d i nadat hulle Christus leer ken het $-\mathrm{vgl} 1: 17-25$ en $2: 9-10)$, en die eindgerig wat Christologies georiënteer sal wees $13: 22$ en $4: 1-6)$.

2.2.3 Op grond van 'n tradisie-historiese en redaksie-kritiese analise blyk dit verder dat die Christologiese lewensperspektief die tradisiemateriaal (wat $\mathrm{d} \mathrm{m} v$ literêre kritiek en tradisiegeskiedenis uitgewys is) oriënteer. ${ }^{15)}$ Ek sal volstaan met ' $n$ voorbeeld of twee. Die Joodse "berakah"-gebed wat normaalweg lui "Geloofd sy die Here, die God van Israel ..." (vgl Psalm 41:14) word in 1:3 Christologies herbeskryf as "Geloofd sy die God en Vader van onse Here, Jesus Christus ..." (Eûlogètos ho theòs kai patèr toû kuríou hèmon 'lèsoû Christoû). Die hellenistiese konsep van "wedergeboorte" (ánagennáo) word eweneens Christologies georiënteer in 1:3 en 1:22-25. Op dieselfde wyse word die Joodse apokaliptiek (1:10-12 en 20-21); eksodus- en ballingskaptradisies (1:13-25); asook godsdienstig-kultiese en sosio-politiese tradisiestof $(2: 4-10)$ Christologies geherinterpreteer en nuwe betekenis gegee. Vanselfsprekend sluit die herinterpretasie van tradisie-materiaal baie nou aan by die herinterpretasie van die veronderstelde kultuurhistoriese leefwêreld. So byvoorbeeld, sou die verwysing na "volk ('éthnos) in 2:9 of die Joodse volk of die etniese groepering in Klein-Asië tydens die eerste eeu voor die geestesoog van die werklike lesers oproep. Op dieselfde wyse sou die "vrykoping" (élutrōthète) in 1:18 of die vrykoop van slawe, of Israel se bevryding uit ballingskap, of die eksodusgebeure voor die geestesoog kon oproep. Wat egter van deurslaggewende betekenis is, is die Christologiese herinterpretasie (oriëntasie) van die verwysing na "volk" (vgl 2:4-10) en "vrykoping" (vgl 1:19). Al hierdie voorbeelde bevestig maar net die feit dat alle geskrifte 'n bepaalde hartsoriëntasie het. In die geval van 1 Petrus is dit 'n Christologiese lewensperspektief. 
2.2.4 Indien dit waar is dat die dinamiese perspektief alle sinduidende kommunikasie oriënteer, spreek dit vanself dat die bundeling (kanonisering) van die 27 Nuwe-Testamentiese geskrifte ook vanuit ' $n$ bepaalde lewensoriëntasie gedoen is. Die feit dat 1 Petrus hierin opgeneem is, bevestig dat hierdie brief aansluit by die geskrifte wat op ' $n$ beslissende wyse getuig van die "nuwe testament" wat gegrond is op die Christusgebeure - dit wil sê Christologies georiënteer is. Dit is egter ' $n$ saak op sy eie en kan hier nie verder aangesny word nie.

Die beslissende rol van die dinamiese perspektief blyk egter ook in die dialektiese komponent van die kommunikasieproses.

\subsection{Die konflikskeppende funksie van die dialektiese strategie}

Ek het reeds betoog dat daar kwalik sprake kan wees van kommunikasie sonder dat die dialektiese komponent verreken word. ${ }^{17)}$ Met die begrip "dialektiese strategie" wil ek juis uitdrukking gee aan die hipotese dat kommunikasie ten diepste ' $n$ "tweegeveg" is. Daarom is die funksie van die dialektiese komponent in tekstuele kommunikasie "konflikskeppend" met die doel om die lesers te oortuig. Dit geld veral vir ideologiese en godsdienstige geskrifte. Daarom sou ons die kommunikasie van die Nuwe Testament kon beskryf as "'n tweegeveg tussen kosmologiese perspektiewe" ( $\mathrm{d}$ i dié van die teks en dié van die leser/s).

In die analise van 1 Petrus het dit geblyk dat die keuse van die teksfunksies en die tekstipes van 'n geskrif die strategie op 'n besondere wyse reflekteer soos dit dan ook noodwendig uitdrukking vind in die statiese teksdwang en dinamiese perspektief van die brief. ${ }^{18)}$

2.3.1 In aansluiting by die insigte van Grosse ${ }^{19)}$ identifiseer ek die teksfunksies wat dwarsdeur 1 Petrus aangetref word as groepsidentifiserend (indikatief) en appellerend (imperatief). Derhalwe kan ons konkludeer dat die brief ' $n$ argumentatief-oorredende strategie het wat groepsgerig is. Dus word die lesers inderdaad uitgedaag tot 'n tweegeveg deur hierdie konflikskeppende strategie. Om die werklik deurslaggewende betekenis van teksfunksies se onderskeie strategieë te bepaal, is die bydrae van Teun van Dijk uiters waardevol. Hy betoog dat die prosesse van "identifikasie" en "vervreemding" (die delikate dialektiek tussen die "bekende" en die "onbekende") die basiese elementêr-binêre struktuur van alle teksfunksies uitmaak. ${ }^{20}$,

(a) 'n Geslaagde skrywer se keuse en ordening van materiaal (statiese gerigtheid) behoort die leser op 'n delikate wyse (strategies) in 'n bepaalde rigting te dwing. In 1 Petrus is hierdie delikate strategie om die 
lesers te laat identifiseer met die skrywersperspektief op 'n meesterlike wyse uitgevoer. Daar is gebruik gemaak van groepsidentifiserende kultiese, liturgiese en sosiologiese meestersimbole (bv emosionele en appellerende OT-aanhalings asook begrippe soos broers, geliefdes, besprenkeling, redding, bloed van Christus, priesterdom, heilige volk, en so meer). Terselfdertyd vervreem die skrywer hulle van hierdie tradisies. Enersyds skep hy afstand en gesag deur sy outeursmandaat (Petrus as apostel van Jesus Christus). Andersyds maak hy gebruik van Christusgeoriënteerde, paradoksale en emosionele godsdienstigsosiologies-politiese kontraste wat dikwels 'n skok-effek op die lesers het. Ons het reeds gesien hoedat die oksimoron in 1:1 die lesers konfronteer deurdat albei elemente van identifikasie (die geadresseerdes as "uitverkorenes" en bevoorregtes) en vervreemding (die geadresseerdes as "vreemdelinge" en uitgeworpenes) opgesluit is. Nog "n voorbeeld waarin hierdie delikate spanning tussen identifikasie en vervreemding pragtig geillustreer word, is die beeld van die geadresseerdes as God se huishouding (oikos pneumatikós - 2:5). In hierdie huishouding word van 'n uiters emosionele rolverdeling van Vader-kinders-broers gebruik gemaak om die lesers te laat identifiseer met hierdie diepgewortelde rolle van die familiestrukture. Ons het egter gesien dat hierdie rolle en verhoudings tussen die aktante, Christologies georiënteer is. Dit het die vervremende (uitdagende) implikasies dat God se huishouding in "vreemdelingskap" leef (paroikía in 1:17 in kontras met bikos in 2:5). So beteken die Vaderskap van God en die broederskap van gelowiges terselfdertyd "vreemdelingskap" in die wêreld - enersyds vanweë hulle vreemde (unieke) Christusgeoriënteerde lewenstyl en andersyds omdat hulle as vreemdelinge verwerp en vervolg word deur die gemeenskap van ongelowiges.

(b) Ons het tot dusver gesien hoe die Christologiese perspektief van 1 Petrus nie alleen die teksdwang soos gemanifesteer in meestersimbole, die implementering van tradisiemateriaal, die beskrywing van aktante en hulle verhoudings herbeskryf en oriënteer nie, maar dat dit ook die basis is van die teksfunksies van "identifikasie" en "vervreemding" (wat van deurslaggewende betekenis is in die kommunikasiegebeure). Die strategie van oorredende tekste (soos Bybelse tekste deurgaans is) is immers om deur middel van die delikate spel van identifikasie en vervreemding in ' $n$ tweegeveg met sy lesers te tree om hulle hopelik te oorreed om dieselfde lewensperspektief te deel. Vanselfsprekend behoort ook die tekstipe van 'n geskrif by te dra tot hierdie teksstrategie.

2.3.2 Met behulp van 'n vormkritiese analise (in die sin van "Gattung-

ISSN 0257-8891 = SKRIF EN KERK Jrg 9(1) 1988 
kritik') en ' $n$ teksvergelykende studie van tekstipes is 1 Petrus as ' $n$ epistolêre omsendbrief te tipeer. Dit gee uitdrukking aan die skrywer se strategie om 'n langafstand gesprek (waarin hy persoonlik afwesig is) aan te knoop via sy geskrif met meer as een groep gelowiges wat geografies verspreid geleef het in Klein-Asië (vgl 1:1). Die feit dat dit 'n omsendbrief is, verklaar ook die afwesigheid van persoonlike opmerkings. Laasgenoemde is tipies van "werklike" briewe in teenstelling met "epistels". ${ }^{211}$ Die strategie van die skrywer was dus klaarblyklik om amptelik ' $n$ belangrike boodskap te kommunikeer met gelowiges in die algemeen binne ' $n$ uitgestrekte geografiese gebied. Kom ons kyk kortliks hoe hierdie strategie in die statiese gerigtheid en dinamiese perspektief na vore gekom het.

(a) Vir bogenoemde strategie het die vorm (tekstipe) van 'n omsendbrief hom uitstekend geleen. Daarom is dit nie snaaks dat die doel en strategie van die skrywer nie alleen uitdrukking gevind het in sy "epistolêre" vorm nie, maar ook in sy statiese teksdwang. So byvoorbeeld vind ons in die afsluiting van die briefkorpus die tradisionele 'égrapsa-formule (d $i$ 'n bepaalde element in die antieke briefvorm) waarin die skrywer self sy doel (waaraan sy strategie uitdrukking gee) beskryf. Dit is volgens 5:12 om die geadresseerdes te vermaan (parakaléó) en te verseker ('epimarturéó) van die genade waarin hulle staan. Hierdie selfaangegewe doel reflekteer en bevestig ook die paradoks van die geadresseerdes se identiteit as "uitverkore vreemdelinge" wat die sleutel is van die teksdwang van die brief as geheel. Ons het reeds onder 2.3.1 gesien dat hierdie paradoks ook uitdrukking gevind het in die verskillende teksfunksies dwarsdeur die brief.

(b) Sommige geleerdes argumenteer oortuigend dat 1 Petrus 'n pseudonieme geskrif is. ${ }^{22}$ ) Netso is daar andere wat Petriniese outeurskap oortuigend verdedig. ${ }^{23)}$ Myns insiens is ons nie in 'n posisie om uitsluitsel hieroor te gee nie. In strategiese terme maak dit egter weinig verskil aan die kommunikasie van die brief. Die pseudonieme outeur se strategie is in elk geval om die gesag van Petrus, die apostel, te gebruik in die oordrag van sy boodskap. ${ }^{24)}$ Indien die pseudonieme outeur daarin sou slaag (soos die geskiedenis van die kanonontwikkeling ook bevestig) om "dieselfde" kosmologiese perspektief as Petrus, die apostel, te kommunikeer, sou die geskrif in elk geval 'n gesagsaanspraak op die geadresseerdes en die gelowiges na hulle gehad het. Dus sou ons kon konkludeer dat die tekstipe en strategie van 'n geskrif ook ondergeskik is aan die kosmologiese perspektief wat alle kommunikasie ten grondslag lê en oriënteer.

Daarom sou ek tot die slotsom wou kom dat die kosmologiese 
perspektief die hoeksteen van die kommunikasie van ou gekanoniseerde tekste is. Dit is nie alleen deurslaggewend in die pretekstuele beplanning (konseptualisering deur die werklike outeur) van 'n geskrif nie, maar bepaal ook die statiese teksdwang, die historiese dinamiek, asook die werklike (metatekstuele) kommunikasiegebeure tussen die teks en sy lesers. ${ }^{25)}$ Alhoewel mens versigtig moet wees om ' $n$ beeld in te veel detail toe te pas, is dit nogtans interessant om uit te wys dat die middelste blokkies van elke vlak van Rubic se kubus die "hoekstene" is wat die verskillende kleure (perspektiewe) van elke vlak bepaal en oriënteer - dit wil sê in terme waarvan die identifikasie van kleurgelyke blokkies en die vervreemding van anderskleurige blokkies plaasvind.

Vir die sinvolle kommunikasie van 1 Petrus is dit derhalwe deurslaggewend dat die perspektief van die lesers in 'n tweegeveg met dié van die teks betrokke raak. Dit was ook die basiese vereiste in die ontvangs van hierdie brief deur sy eerste lesers. In die lig van die Christologiese oriëntasie van 1 Petrus sou hierdie brief meer as een konkrete situasie in die eerste eeu na Christus sinvol kon aanspreek. ${ }^{26}$ ) Eerstens sou dit lou Christene wat roem op hulle uitverkorenheid deur hierdie brief kon konfronteer met hulle andersheid (vreemdheid) wat hulle moet uitleef. Tweedens sou dit moedelose Christene wat vanweë hul vreemdelingskap verworpe en verstote voel, kon konfronteer en vertroos met die feit dat hulle God se "uitverkore" kinders is. Derdens sou dit (soos Elliott aanvoer) 'n kombinasie van bogenoemde omstandighede kon wees wat tipies is van minderheidsgroepe (sektes) wie se identiteit as uitverkorenes of heiliges vir hulle selfbeeld belangrik is, maar wat terselfdertyd moet waak om nie hulle andersheid (vreemdheid) prys te gee deur aan gemeenskapsdruk toe te gee nie. Elliott het dan ook meesterlik aangetoon dat faktore soos die geografies rykgeskakeerde en plattelandse georiënteerde Klein-Asië in die eerste eeu na Christus, asook die sosiologiese profiel van minderheidsgroepe (vanweë stammigrasie en staatsverskuiwing van groepe) die sosiokulturele bande van die gemeenskappe in Klein-Asië so geaksentueer het dat diskriminasie teen buitestaanders aan die orde van die dag was. Die punt is dat die historiese omstandighede van die lesers (hetsy kort voor of tydens Nero se vervolging, wat Petriniese outeurskap regverdig; of alledaagse diskriminasie in Klein-Asië gedurende $65-90 \mathrm{nC}$ wat pseudonimiteit vereis; of amptelike vervolging gedurende 93-96 tydens Domitianus se keiserskap; of $115 \mathrm{nC}$ tydens Trajanus se keiserskap wat.pseudonimiteit of deuteronimiteit veronderstel) nie deurslaggewend is vir die kommunikasie van die geskrif nie. Wat wel noodsaaklik is, is die historiese (buitetekstuele) verbondenheid van die lesers aan Jesus Christus as die "ultimate reference" of kosmologiese oriëntasie van hulle lewens. Alleen op grond van hierdie veronder- 
stelde inter- en buitetekstuele kennis van en verbondenheid aan Jesus Christus, word die moontlikheid en openheid vir sinvolle kommunikasie met 1 Petrus gewaarborg.

\section{Voorlopige rigtingwysers in die kommunikasie van ou geka- noniseerde tekste vir sekondêre lesers}

$\mathrm{Na}$ aanleiding van my oefenlopie om 'n multidimensionele kommunikasiemodel op 1 Petrus toe te pas, sou ek graag ten slotte 'n paar voorlopige (!) rigtingwysers vir die kommunikasie van ou gekanoniseerde tekste met sekondêre lesers wou onderstreep. Ek wil my konklusies laat aansluit by ' $n$ opmerking van Umberto Eco: "As far as the problem of textual levels is concerned, one could say that there are more things in a text than are dreamt of in our text theories. But there are also 'fewer' things than are dreamt of." ${ }^{\prime 27}$ )

Die eerste deel van Eco se stelling bevestig dat tekste multidimensionele verskynsels is. Dit impliseer dat ' $n$ multidimensionele benadering ook vereis word om reg aan die eie aard van ou gekanoniseerde tekste te laat geskied. Waarskynlik is die eendimensionele benaderings van die verlede enersyds toe te skryf aan die denkstrome van die onderskeie tydvakke en andersyds, dat geleerdes nagelaat het om tekste as deel van ' $n$ "kommunikasieproses" te verreken.

Die tweede deel van Eco se opmerking veronderstel dat daar tog iets basies aan kommunikasie is en dat dit deel uitmaak van die alledaagse lewe en ervaring van elke mens. Ek meen dat ons ook hierdie basiese insig dikwels nagelaat het wat die kommunikasie van die Bybel betref. Ons het dikwels die Bybel oorgeïnterpreteer en verduister deur daarvan ' $n$ antwoordboek te maak op al ons vrae - hetsy wetenskaplik, histories, liturgies, teologies, of eties. Daardeur het ons die eenvoudige geloofservaringe en singewing (kommunikasie) van die Bybelskrywers aan hulle onderskeie wêrelde (inderdaad vanuit 'n besondere perspektief) verruil vir ons ingewikkelde en verabsoluteerde teologiese konstruksies.

Die uitdaging is dus om die "eenvoud" van 'n multidimensionele kommunikasieproses vas te vang en in ' $n$ sinvolle en werkbare model te omskep. Sodoende kan daar dan voldoen word aan die eis om ou gekanoniseerde geskrifte as deel van alledaagse en menslike kommunikasie te verstaan. Ek het betoog dat die ingewikkelde netwerk van dimensies en modi saamgevat kan word in die begrippe "statiese teksdwang", "dinamiese perspektief" en "dialektiese strategie" en hulle onderskeie funksies van reliëfkartering, oriëntering en oorreding. In die lig van hierdie fokus op die prosesse binne die kommunikasiegebeure, word die ontoereikendheid en naïewe skeiding van teksimmanente, historiese en teolo- 
giese analises en hulle metodes aan die kaak gestel (vgl die appendiks). Die multidimensionele oefenlopie in my doktorale verhandeling waarin 'n magdom teksimmanente, historiese en teologiese metodes toegepas is op 1 Petrus, bevestig (paradoksaal genoeg!) dat die verskillende metodes slegs deelfasette van die statiese, dinamiese en dialektiese komponente van kommunikasie belig. Daarom bly dit belangrik om die beperkinge van die verskillende metodes en die doel waarvoor hulle ontwerp is, raak te sien.

Hierdie multidimensionele kommunikasiemodel sou mens egter kon bevry van 'n metodebeheptheid, terwyl dit terselfdertyd ' $n$ mens in staat kon stel om reg te laat geskied aan die multidimensionaliteit van die kommunikasiegebeure. Afhangende van die teikengroep (hetsy vakkenners, studente of lidmate) kan die onderskeiding van hierdie drie komponente en die drie basiese prosesse binne die kommunikasiegebeure, aangeleer word deur van verskillende asook meer of minder gevorderde metodes gebruik te maak. Vir lidmate sou mens selfs 'n eenvoudige leesprosedure kon aanleer (vgl die appendiks). Daarom is dit nie onmoontlik om selfs vir laerskootkinders 'n leesprosedure aan te leer waarin hulle bedag daarop gemaak word om 'n Bybelboek nie as 'n "pannekoek" te hanteer nie, maar te let op meer en minder belangrike gedeeltes daarin; te onthou dat elke geskrif ' $n$ "hart" het wat ons moet raaksien as ons dit wil verstaan; en laastens dat die lees van die Bybel ten diepste 'n "tweestryd" is om die leser te oortuig van wat werklik die mens se bestaan die moeite werd maak. Twee onafhanklike eksperimente (die eerste met ' $n$ stadsgemeente in Port Elizabeth en die tweede met swart maatskaplike werkers in Transkei) het die moontlikhede van so ' $n$ multidimensionele benadering vir lidmate bevestig.

Samevattend stip ek slegs die belangrikste rigtingwysers en moontlikhede van ' $n$ multidimensionele kommunikasiemodel aan. ${ }^{28}$,

3.1 Wat die teksdwang betref het ons gesien dat dit reg wil laat geskied aan die outonomie van die gestolde statiese teks. Behalwe dat die skrywers van die Bybelboeke ir elk geval nie meer leef nie, het hulle willens en wetens hul eie identiteit laat opgaan in hul onderskeie geskrifte. Daarom is die analise van die gestolde teks, kronologies die vertrekpunt in ons rekonstruksie van die kommunikasie van ou gekanoniseerde geskrifte. Met behulp van verskeie metodes (wat ten diepste slegs gereedskap is om ' $n$ bepaalde werk te verrig) kan die kronologiese, hiërargiese, mosaïese en estetiese reliëf (teksdwang) blootgelê word. Op hierdie wyse word daar rekenskap gegee van die statiese komponent in die tekstuele, historiese en teologiese dimensies.

Dit beteken dat daar rekening gehou sal moet word met ' $n$ 
bepaalde multi-interpreteerbaarheid in tekstuele kommunikasie vanweë die feit dat die statiese komponent ook 'n historiese en perspektiwiese dinamiek besit wat meerduidig is. Vergelyk in hierdie verband die beredeneerde verskille met betrekking tot inleidingsvraagstukke soos outeurskap en datering, asook taalkundige fasette soos kolaverdeling en -groepering, perikoopverdeling en -groepering, onderskeiding van temas en subtemas, en so meer. Deur hiermee rekening te hou sal ons gevrywaar word van die "poetic fallacy" wat die kommunikasie van 'n teks beperk het tot die "poëtiese" struktuur en retoriek binne die teks. Voorstanders van laasgenoemde vergeet gerieflik dat Bybelse tekste dikwels slegs verstaan kan word met behulp van 'n historiese verwysingsraamwerk (vgl die vreemdheid van die Bybelse leefwêreld) en 'n buitetekstuele dialektiek tussen die onderskeie perspektiewe van die teks en die ontvangers.

Alhoewel die statiese komponent inderdaad ' $n$ bepaalde multiinterpreteerbaarheid vertoon, stel die gerigtheid van die tekstuele dimensie besliste grense daar wat die leser in ' $n$ bepaalde rigting van interpretasie dwing. Die statiese komponent van die kommunikasieproses is inderdaad ' $n$ noodsaaklike korrektief op die "indeterminate fallacy" waarin die meerduidigheid van tekste verabsoluteer word tot 'n totale relativisme. Dit is ' $n$ gevaar wat ondanks die waardevolle bydraes van die tekspragmatiek vir die kommunikasie van tekste, in bepaalde strominge binne die resepsie-estetika dreig.

3.2 Wat die dinamiese perspektief betref, het ons gesien dat dit reg wil laat geskied aan die historiese dinamiek van die kommunikasiegebeure. Hierdie bepaalde fokus op die primêre doel van die historiese analise $(\mathrm{d} i$ om die perspektief te bepaal) het myns insiens die moontlikhede om nuwe lewe te blaas in die steriele en kliniese histories-kritiese benadering. Dit is nie alleen ' $n$ stimulerende uitdaging om die hartsoriëntasie (lewensperspektief) van 'n geskrif te probeer vasstel nie, maar dit is immers ook noodsaaklik voordat Bybelse geskrifte hoegenaamd sinvol met sekondêre lesers sal kommunikeer. Ek het reeds daarop gewys dat die kosmologiese perspektief die hoeksteen van skriftelike kommunikasie is. Dit is nie alleen die oriëntasiepunt van die pretekstuele konseptualisering van die geskrif as die outeur se herbeskrywing van die werklikheid nie, maar dit vind ook neerslag in die gestolde teks (statiese komponent) terwyl die betrokke tekstuele perspektief (dinamiese komponent) met die leser in 'n tweestryd gewikkeld wil raak (dialektiese komponent).

Die verrekening van die kosmologiese perspektief is ' $n$ belangrike korreksie op sowel die "poetic fallacy" wat slegs fokus op die statiese teks, die fundamentalisme wat geneig is om elke woord en vers op die- 
selfde vlak te sien en direk op vandag toe te pas - dikwels sonder dat die "hartsoriëntasie" of historiese dinamiek (met name die proses van die herbeskrywing van die werklikheid vanuit 'n bepaalde perspektief) van die geskrif verreken is. Dit skep ook moontlikhede om die verskeidenheid van temas wat deur verskillende navorsers as die sentrale boodskap van 'n geskrif gesien is, sinvol in relasie tot mekaar te plaas en te oriënteer aan die kosmologiese perspektief van 'n geskrif.

Verder bied die begrip "kosmologiese perspektief" ook 'n korreksie op die "referential" en "genetic fallacies" van 'n konsekwent historiese benadering. Die verwysing ("reference") na die buitetekstuele wêreld is nie 'n een-tot-een-relasie nie, maar is 'n semantiese aangeleentheid ${ }^{29}$ ) waarin die perspektief van die outeur ' $n$ deurslaggewende rol speel. Die oorsprong ("genesis") van 'n teks is in terme van outeurskap, geadresseerdes en datering (wat dikwels meerduidig en multi-interpreteerbaar is) ook nie deurslaggewend vir die verstaan van 'n geskrif nie, maar weer eens die kosmologiese perspektief. Wat wel in die relasie teks:werklikheid van deurslaggewende betekenis is, is die buitetekstuele verwysing (di "reference behind the text") ${ }^{30)}$ of werklikheidsrelevansie van die tekstuele perspektief ( $d w s$ in die sin van ' $n$ betekenisvolle en werklikheidsgetroue singewing). Hierin is die gesaghebbendheid of kanonisiteit van 'n geskrif opgesluit. Wat die eerste Petrusbrief betref het dit dus te make met die werklikheidsoriëntasie en relevansie van die Christologiese perspektief. Ons het egter ook gesien dat die buitetekstuele oriëntasie van die werklike lesers (di "reference before the text") deurslaggewend is vir die kommunikasie van ou gekanoniseerde tekste. Wat 1 Petrus betref, beteken dit dat die lesers se werklike oriëntasie (verbintenis) aan Jesus Christus van kardinale belang is vir sinvolle kommunikasie.

3.3 Die dialektiese strategie wil, in aansluiting by bogenoemde, eenvoudig onderstreep dat kommunikasie ten diepste 'n "tweestryd tussen perspektiewe" is - tussen dié van die teks en dié van die lesers. Hierin is die eenvoud van skriftelike (ook alledaagsel) kommunikasie geleë. Terselfdertyd is dit 'n uitdaging om "in 'n dialektiese gesprek te bly" of 'n "openheid te hê" vir die perspektief van die geskrif. Sonder hierdie tweestryd (dialektiek) van die identifikasie en vervreemding tussen perspektiewe kan daar nie sinvolle kommunikasie plaasvind nie.

Bogenoemde definisie van interkommunikasie as "'n tweestryd tussen perspektiewe" sluit die "positivistic fallacy" uit wat die geslaagdheid van die verstaan van die Bybel verbind aan of die vermoëns van teksimmanente of histories-kritiese metodes. Elke mens lees immers die Bybel vanuit sy perspektief en geen metode kan sinvolle kommunikasie waarborg nie. Uiteindelik is sinvolle kommunikasie slegs geleë in die be- 
reidheid en openheid om in hierdie onophoudelike tweestryd, hoe langer hoe meer, oortuig te word van die betrokke geskrif se kosmologiese perspektief. In dié sin kan die "gesag van die Skrif" nog betekenisvol verreken word binne hierdie kommunikasiemodel. Verder korreleer dit ook met die heersende insigte in die wetenskapsfilosofie wat die voorlopige, sosio-historiese en relasionele bepaaldheid van ons kennis van die waarheid onderstreep. ${ }^{31}$ ' Andersyds sluit hierdie model aan by die kritiese realisme en wel op die punt dat die "affective fallacy" (wat elke moontlike subjektiewe verstaan as geldig aanvaar) aan bande gelê word. In my kommunikasiemodel word dit vermy deur die werklikheid van die statiese teks en sy reliëfkarterende funksie asook die dinamiese perspektief en sy kosmologies-oriënterende funksie in die kommunikasieproses, te verreken. Vanweë die perspektiwiese aard van kommunikasie (wat die verwerwing van kennis insluit) bly ons egter vasgevang in die "dialektiek" van die kommunikasiegebeure.

Binne hierdie kommunikasiemodel is dit dus moontlik dat die kosmologiese perspektief van 1 Petrus in 'n tweestryd met sy lesers (aanvanklik met die primêre lesers, maar later ook met sekondêre lesers) tree, met die doel om hulle te oriënteer aan 'n Christologiese lewensperspektief. In die paradoks van die kruis en opstanding van Jesus Christus word mense uitgedaag om die diepste sin vir hulle bestaan in hierdie kosmos te vind. Dit was juis in Jesus se lewensoriëntasie aan God, die liefdevolle Vader en die regverdige Regter, dat Hy ook betekenis kon gee aan 'n sinlose en onregverdige kruisdood. Hierdie Christologiese lewensperspektief daag ons uit om ons kosmologiese perspektiewe en singewing hetsy polities in terme van die een of ander beleid (apartheid, integrasie of assosiasie); hetsy ekonomies in terme van die een of ander bestel (kapitalisme, sosialisme of vrye onderneming); hetsy akademies in terme van die een of ander model (histories, taalkundig, kommunikatief, multidimensioneel of krities-realisties) - te relativeer ten opsigte van die "vrede in Christus".

Hiermee erken ek uiteraard die voorlopigheid en gebrekkigheid van my eie model en dat dit in die laaste instansie nie die sin van my lewe bepaal nie. Na my beskeie mening is daar egter vier pluspunte aan hierdie model verbonde. Eerstens is hierdie model bruikbaar vir vakkenners en lidmate vanweë die feit dat dit fokus op die basiese prosesse in die kommunikasiegebeure wat selfs kinders kan verstaan omdat hulle dit self daagliks beleef. Tweedens maak ' $n$ multidimensionele benadering mens bedag daarop om nie ' $n$ bepaalde metode te vergoddelik nie, maar rekening te hou met God se veelkleurige genade (waarheid). Derdens plaas hierdie model die Nuwe-Testamentiese eksegese en hermeneutiek binne ' $n$ meer omvattende kommunikasieraamwerk. Die toepassing hiervan op 
1 Petrus het, myns insiens, inderdaad tradisionele eksegetiese "turksvye" gerelativeer en nuwe moontlikhede vir Bybeluitleg gesuggereer. Vierdens skep die siening van menslike kommunikasie (di interaksie met die wêreld) as "'n stryd tussen kosmologiese perspektiewe", wel die ruimte vir die mens om sy lewensin in God, die gans Andere, te vind. Dit is juis hierdie Christologiese oriëntasie van die kruisparadoks van 1 Petrus wat ons as Christene van ons mensgemaakte modelle, valse sekerhede en hoogheidswaan wil bevry, sodat ons met ons hele hart (in vreugde en smart), verstand (met kinderlike onbevangenheid) en al ons kragte (met ons hele wese) soekers kan wees na God se koninkryk van liefde en geregtigheid ... totdat $\mathrm{Hy}$ kom. ${ }^{32)}$

\section{NOTAS}

1. Hierdie artikel is 'n oorsigtelike weergawe van $\mathbf{J}$ Rousseau, $A$ multidimensional approach towards the communication of an ancient canonized text: Towards determining the thrust, perspective and strategy of 1 Peter, DD-proefskrif, Universiteit van Pretoria 1986. Die proefskrif is voltooi onder promotorskap van professor A B du Toit. Hiermee wil ek my opregte dank aan hom betuig vir die professionele bekwaamheid en integriteit waarmee hy my tydens my doktorale studies begelei het.

2. Vergelyk Rousseau, aw, 1986, 70-72.

3. Lees in hierdie verband die interessante artikels van S M Schneiders, "From exegesis to hermeneutics: The problem of the contemporary meaning of Scriptures", Horizons vol 8 (1981), 23-29; en "The paschal imagination: Objectivity and subjectivity in New Testament interpretation", Theokgical Studies vol 43 (1982), 52-68. Vergelyk ook Rousseau, aw, 1986, 19-28.

4. Dit word weerspieël in die chaos van uiteenlopende navorsingsresultate met betrekking tot 1 Petrus - vgl Rousseau, aw, 1986, 4-28. Dit geld egter ook vir die NuweTestamentiese wetenskap as geheel - vgl J Rousseau, "Die Woord, waarheid en (Nuwe-Testamentiese) wetenskap", Scriptura vol 16 (1985), 1-16.

5. Rousseau, aw, 1986, 29-77; kyk ook H F Plett, Textwissenschaft und Textanalyse: Semiotik, Linguistik, Rhetorik, Heidelberg 1975, 11-13; asook T A van Dijk, Textwissenschaft: Eine interdisziplinaere Einführung. München 1980, 1-3.

6. Kyk Maletzke se model in D Mcquail \& S Windahl, Communication models for the study of mass communication, New York 1981, 36-41; Grosse en Plett se modelle in E U Grosse, "Was ist Semiotik? (Teil 1): Eine Exemplifizierung am Novellenwerk Maupassants", Linguistica Biblica vol 52 (1982), 87-113 en Plett, aw, 1975, 40-46; en die integrering van die drie in Rousseau, aw, 1986, 35-38.

7. Plett, aw, 1975, 46-51.

8. Kyk Rousseau, aw, 1986, 48-51 waar gepoog word om die insigte van Plett 'n paar stappe verder te neem en 'n kommunikasiemodel vir ou antieke tekste daar te stel. $\mathrm{Vgl}$ ook die vereenvoudiging van dié model soos toegepas deur A E J Mouton, 'n Eksegeties-hermeneutiese verkenning van die en Christo-kernbelydenis by Paulus na aanleiding van Efesiërs 1:3-14, MA-verhandeling: Universiteit van Port Elizabeth 1987.

9. Rousseau, aw, 1986, 97-432.

10. Vgl Rousseau, aw, 1986, 107-109 \& 398; asook U Eco, The role of the reader: 
Explorations in the semiotics of texts, London 1979, 23 \& 27-31; en Van Dijk, aw, $1980,45-49$.

11. Rousseau, aw, 1986, 228-260, 372-373 \& 425-427.

12. Dit word in detail bespreek in Rousseau, aw, 1986, 97-131.

13. Dit is binne hierdie konteks dat die resente insigte van veral die kommunikasiekunde, teksteorieë, die sosiologie van kennis asook die wetenskapsfilosofie, die deurslaggewende belang van 'n lewens- en wêreldbeskouing vir die mens se interaksie met sy wêreld uitgewys het - vgl Rousseau, aw, 1986, 65-68, 111-113 \& 87. Dit is te begrype dat ons tans ' $n$ stortvloed van woorde het wat min of meer na dieselfde saak ("lewens- en wêreldbeskouing") verwys, bv "myth" (Levi-Strauss), "universal square" (Greimas), "semantic universe" (Daniel Patte), binne die strukturalisme - vgl R F Collins, Introduction to the New Testament, London 1983, 242-251; "simbole". "metafore" en "grondmetafore" binne die semiotiek en taalkunde - vgl Eco, aw, 1979; J M du Preez, "n Kommunikatiewe studie van geskrewe sekondére onderrigsmateriaal in Suid-Afrika, MA-verhandeling UNISA 1983, 1-8; "symbolic universe", "world", "recipe knowledge" en "ideologie" binne die kennissosiologie - vgl N Petersen, Rediscovering Paul: Philemon and the sociology of Paul's narrative world, Philadelphia 1985, 53-65; "epistemologie", "ultimate commitment" en "paradigmas" binne die wetenskapsfilosofie - vgl JW V van Huyssteen, Teologie as kritiese ge/oofsverantwoording: Teorievorming in die sistematiese teologie, Pretoria 1986, 3-6.

14. Kyk ook my definisie in Rousseau, aw, 1986, 404. Vir 'n aktuele toepassing van die onderskeid tussen perspektief en meestersimbole lees ook J Rousseau, "Bybelkunde as skoolvak: 'n Toekomsvisie", Scriptura (verskyn eersdaags).

15. Vgl Rousseau, aw, 1986, 371-385 \& 428-429.

16. Vgl Rousseau, aw, 1986, 244-260 \& 428-429.

17. Die verrekening van hierdie aksent reflekteer op ' $n$ besondere wyse die klem wat tans gelê word op die pragmatiek en resepsie van tekste. In hierdie verband is ek veral beïnvloed deur onder andere Eco, aw, 1979; E U Grosse, Text und Kommunikation: Eine linguistische Einführung in die Funktionen der Texte, Stuttgart 1976; W Iser, "The reading process: A phenomenological approach" in R Cohen (red), New directions in literary history, London 1974, 125-145; Plett, aw, 1975; P Ricoeur, "Biblical hermeneutics", Semeia vol 4 (1975), 27-148; Van Dijk, aw, 1980: 135-159; en J van Luxemburg et al., Inleiding in de literatuurwetenschap, Muiderberg ${ }^{2} 1982$.

18. Vgl Rousseau, aw, 1986, 351-370 \& 430-432.

19. Grosse, aw, 1976.

20. Vgl Van Dijk, aw, 1980: 135-139. Die basiese binêre struktuur van rekenaartaal (di kombinasies van "nul" en "een") bevestig die teorie van Van Dijk en kan myns insiens ' $n$ interessante perspektief bydra tot die basiese strategieeë van tekstipes kyk Rousseau, aw, 1986, 353.

21. Kyk L Goppelt, Der erste Petrusbrief, Göttingen 1978, 45; en N Brox, Der erste Petrusbrief, Neukirchen-Vluyn 1979, 24.

22. Kyk veral Brox, aw, 1979, 226-230. Vgl ook sy artikels "Zur pseudepigraphischen Rahmung des ersten Petrusbriefes", Biblische Zeitschrift (Neue Folge), vol 19, 78-96; en "Tendenz und Pseudepigraphie im ersten Petrusbrief", Kairos (NF) $1978,110-120$.

23. Vgl die bespreking van die voor- en teenstanders van Petriniese outeurskap in Rousseau, aw, 1986, 6-8.

24. Kyk die beredenering in Rousseau, aw, 1986, 360-361 \& 366.

25. Vgl Rousseau, aw, 1986, 418-422. 
26. Kyk die bespreking en motivering vir die verskillende "Sitze im Leben" in Rousseau, aw, 1986, 257-259. Die bydrae van J H Elliott, $A$ home for the homeless: A sociological exegesis of 1 Peter, its situation and strategy, London 1981, is in hierdie verband uiters prikkelend - ondanks die feit dat hy nie daarin geslaag het om die "referential fallacy" te vermy nie.

27. Eco, aw, 1979, 38.

28. Die rigtingwysers wat hier volg, is 'n seleksie van my stellinge met betrekking tot die metatekstuele kommunikasie van ou tekste soos in hoofstuk IV van Rousseau, aw, $1986,388-432$, vervat is.

29. Kyk W S Vorster, "'Formgeschichte' en 'Redaktionsgeschichte' ", in A F J Klijn (red), Inleiding tot de studie van het Nieuwe Testament, Kampen 1982, 108.

30. Vgl Schneiders, Theological Studies vol 43 (1982), 62-65.

31. Kyk Rousseau, aw, 1986, 75-90.

32. Vgl Rousseau, Scriptura vol 16 (1985), 15. 
APPENDIKS: SAMEVATIENDE TABEL

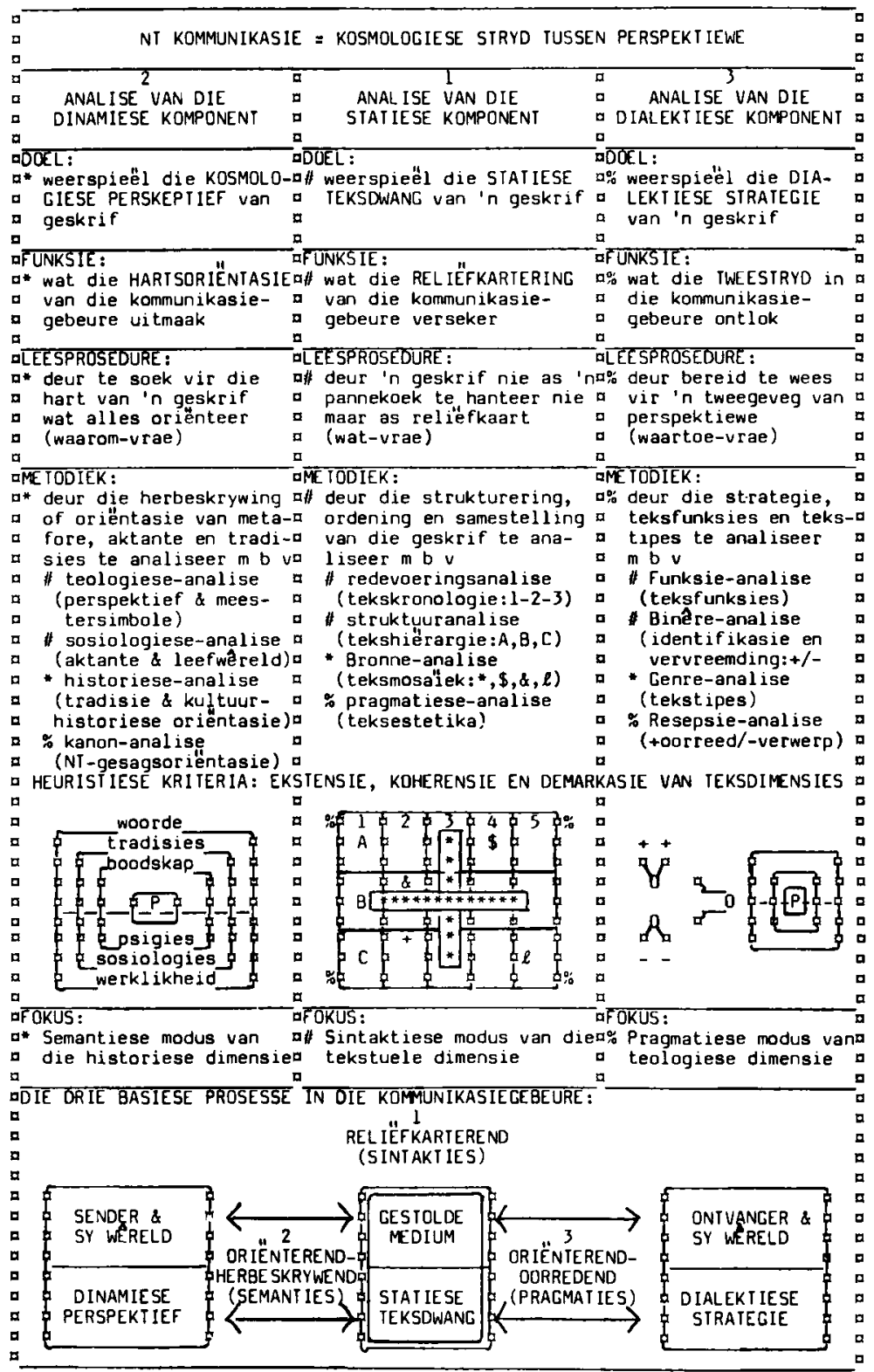

